\title{
Concerning the Transition of the Reception of the Music Video due to a Change in the Politics of Distribution of the Music Video- and the Music(-TV-)Market ${ }^{1}$
}

\author{
Axel Schmidt/Klaus Neumann-Braun
}

\section{IntROdUCtION}

The reception of the music video (abbreviated as 'ROTMV' throughout this chapter) was attached in the past mainly to the medium of television, hence for a research upon the audience the private resp. the public TV-setting served as the point of reference. Recently, technical and developments related to politics of the market have made that the audience dispersed on another, higher level of complexity. Taking this into account, the following paper deals with the changed conditions of the ROTMV.

However, such a reception can be researched in many different ways. Thus, we first want to make clear in which respect we are approaching the topic of the ROTMV.

First, reception can be understood as referring to the cognitive processing of the specific media genre, in this case the music video, which provokes questions about how music video is constructed in the first place. Furthermore, the question could be pursued in a quantitative respect, i.e. in the form of data concerning its use. However, in order to pursue yet another consideration of how ROTMV has changed, neither cognitive processing nor quantitative analysis pursued here, except with respect to secondary data.

This consideration takes as a starting point the question of where and how the phenomenon of the ROTMV can be (still) encountered today, particularly by embedding the question of reception within the research of media culture in social-economical and socio-cultural contexts. One then has to ask questions concerning the associated, flanking conditions 
of processes of reception. In other words, before it can be explained how reception happens cognitively resp. quantitatively, it has to be cleared, under which conditions resp. in which structures ROTMV is happening today.

Connected herewith are the following questions:

- Does the classic music video still exist, and if so, in which respect?

- Are there flexible boundaries between the music video and other AVformats?

- How and by which means are clips distributed today?

- In which media environments are clips encountered?

- Which entities produce and distribute clips to which means?

- What is the role of music TV stations in this context?

- In which way have the offered choices and the programs of the classic music TV stations changed?

The main focus of the following consideration falls upon dealing with these questions by giving a sketch of the structural conditions of the ROTMV, i.e.: to sketch the structures of the "context of reception" in a perspective which combines the historical with the systematic.

For this purpose, we are relying on web-based researches, current literature, and interviews with experts which were the base for a finished book project with the title "Viva MTV - reloaded".

The following overview should make clear the greater context of argument as well as its direction alongside the ROTMV-topic, as chosen for the paper:

A. Music video and music television yesterday: interlinking

- The genesis of music television: innovation (“cult”) and development towards a "Monopoly Television"

- Routine: the ideal-typical way of functioning

B. Music video and music television today: a double-sided decoupling

- Crisis: collapse of the ideal-typical way of functioning and becoming every day-like 


\begin{tabular}{|c|c|c|}
\hline Reasons/Causes & $\begin{array}{l}\text { Reactions of the } \\
\text { music channels }\end{array}$ & Way of change \\
\hline $\begin{array}{l}\text { - Crisis in the music } \\
\text { industry/structural } \\
\text { change of the classical } \\
\text { record industry } \\
\text { - Change of the TV-/ } \\
\text { media-landscape } \\
\text { (keyword: digitalisation) }\end{array}$ & $\begin{array}{l}\text { Dissolution of the } \\
\text { boundaries of the music } \\
\text { television: } \\
\text { - From being a division } \\
\text { channel to the full } \\
\text { program } \\
\text { - New ways of distribution } \\
\text { - Extension of partnerships }\end{array}$ & $\begin{array}{l}\text { Discontinuity: } \\
\text { More Than } \underline{\text { Videos }}\end{array}$ \\
\hline $\begin{array}{l}\text { music video } \\
\text { - on the level of the } \\
\text { genre (from the video } \\
\text { clip to the net clip) } \\
\text { - on the level of } \\
\text { distribution (music } \\
\text { videos on the internet) }\end{array}$ & $\begin{array}{l}\text { Extension of the monopoly } \\
\text { (in Germany: “MTVIVA”) }\end{array}$ & $\begin{array}{l}\text { Continuity: } \\
\text { Monopoly } \\
\text { Television }\end{array}$ \\
\hline
\end{tabular}

C. Conclusion: Changed (conditions of) reception

The central aspects appear in bold. Aspects which are only sketched appear as regular text, and those only hinted upon here appear as grey. The purpose of this synopsis is to make clear the greater context of the argument without having to repeat it throughout this paper.

Point A deploys the thesis of the interlinking of the music video and music television ("yesterday"), i.e. music video and music television forged an alliance which in the phase of the genesis did stand for innovation. MTV then becomes "cult" (as can be seen, for instance, by the success of the "I want my MTV" campaign [1982]). Subsequently, MTV developes into a global player, into a "Monopoly TV" which dominates the market. Thus, a routine is established, a lucrative ideal-typical way of functioning, which then - as argued under point B - gets into a crisis.

This happens - as will be shown - via a double-sided dissociation, which means that music television as well as the music video succumbs to a dissolution of boundaries which then condition the dissociation in their turn.

The dissolution of the boundaries of music television can be finally understood concerning the way of change as a discontinuity ("More than Videos") on the level of the media products (program, music videos), while the remaining components - the crisis of the music industry and the extension of a monopoly (in the German-speaking market: "MTVIVA") could be taken as aspects of the production under the aspect of continuity and have here been mentioned just for the sake of completeness. 


\section{A. Music Video and Music Television YESTERDAY: INTERLINKING ${ }^{2}$}

The fact that MTV today can still operate as a global player in almost monopoly-like structures stems directly from the "cult"-status the channel established from the very beginning. Indeed the value of the brand 'MTV' still benefits from its original cult standing, particulary in combination with the establishment of a new business model. By furnishing the music channel with music videos from music industry, advertisement and programming became the same thing. Contrary to the radio media with their concurrence, MTV in its beginnings could rely on an almost costneutral program which in an increasingly fragmented TV-market became more and more important. If the chain of the creation of value did work, a produced music video supported the selling of records while favoring the use and connection to a TV-channel. Thus, concerning the possibility of presenting the products of the major labels to the related target group, the music channels were the most important marketing instrument for a long time. During its peak period, 80 percent of the video clips shown by VIVA and MTV came from the four biggest record companies Universal, Sony BMG, Warner and EMI. In other words, the marketing model of music television was essentially based on having "found" a media form at the right time which in the crossing fields of the 'economy 1' (viewer/ TV ratings) and the 'economy 2 ' (gains and effects of the advert) functioned as advertising and programming at the same time.

\section{B. Music Video and Music Television TodaY: Double-Sided Decoupeling}

Seen from a contemporary viewpoint, one can state that this relatively harmonious model fell under pressure, if not even into a crisis. The main reasons for this downfall were and still are the crisis of the music industry and the resulting structural change of the classic record industry on the one hand and the changed media and TV-landscape, as well as the connected needs of the receiving audience on the other hand. Neither point can be developed here, but it is enough to note at this point: When considered as an aspect of the music business, music videos have lost their importance as a means of marketing and partly can't be financed anymore; when being considered under the aspect of the TV market and the changed media landscape (keyword: digitalization, mobile media) they undergo decisive changes which concern less the classic music video as such (it still exists), but more the social and media-economic context in which music videos have to compete now.

Importantly, this means a slow marginalization of the classic commercial music video as the linchpin of the own business and program- 
ming politics and has thus modified the music video and its reception decisively.

We have tried to sum up these developments with the notion of the "double sided decoupling on the level of the product", which means that the once very close linking of music videos and music television on the side of the music video as well as on the side of the music television has been loosened. We have used the notion of the "dissolution of the boundaries" for this process whereby the dissolutions of the boundaries of the music video are resulting in the dissolution of the boundaries of music television.

A dissolution of the boundaries of the music video has to be stated on the level of the genre. Here the range has been - roughly put - widened by now to include so-called "net clips" which means that they are recycled (i.e. usually taken from mass media) or self generated AV-excerpts which are accessible on the Internet via related video-portals such as YouTube, clipfish or MyVideo. The following types can be roughly discerned which have participated in the dissolution of the boundaries of the classic music video:

- Fragments /alienations of music videos (remixes, generated by users)

- Re-elaborations by the channels (for example the show "MTV Mash" [2003]; other remixes of music videos)

- Imitations of the genre

- Adaptation of an aesthetic of the classic clip-genre

- Filmed live-concerts as music clips

- Any other connection of sound and vision which belongs to a floating continuum of the music video (domination of the music; singing/ performance) and film/TV (domination of the images; spoken words; soundtrack-function of music).

- Video clips used as ringtones on mobile phones (so-called "videotones")

Moreover there is a dissolution of the boundaries on the level of distribution, since music videos are lo longer coupled with the mass medium 'TV'. One therefore has to deal with "old" contents (music videos) in a frame of new, i.e. net- or mobile-based choices. Here, the following types can be roughly discerned concerning their "distribution channel":

- music videos on Web 2.o-platforms

- music videos on net supplies associated to music channels (for example MTV Overdrive)

- music videos on net supplies in cooperation with music channels (for example Joost)

- music videos on net suppliers which are not associated to music channels (for example www.popzoot.tv; tunespoon.tv)

- music videos on the homepage of individual artists

- music videos on the mobile phone 
Additionally on could discern which institution is distributing, i.e.

- the artist him or herself

- the users (Web 2.0)

- possibly "net channels" (commercial/professional; similar to mass media)

- classic music television

The music channels are reacting upon these dynamics, with a movement of the dissolution of the boundaries on the product and distribution level, i.e. by broadening their program and by diversifying their ways of distribution.

The development of the contents of the program of MTV can be understood as the way from a pure channel for music towards the classic full program, where the sole focus on popular music has increasingly been abandoned in favor of a broader orientation towards pop- and lifestyletopics of various kinds. Here, a central reason lies in the social-cultural changes which have made popular music lose its profile: Since music is no longer considered to be mainly formative, it cannot provide means for any kind of distinction anymore. Identifiable and distinct youth sub cultures for example have been increasingly substituted by a general youthcultural orientation respectively they have stepped into higher age groups. Thus, the more pop music and life-style have merged, the more MTV has started increasingly aiming for other potentials of distinction than just (pop)music (consumed today also by people older than 40 years) in order to (further) reach their youthful audience. Hence, the distinction towards the generation of the parents functions - at least in its form of (music) television - today much less via musical predilections than according to visual boarders of taste and aesthetics and via questions about public (non-)showing. This is especially true concerning so-called "reality shows" and "docu-soaps" which in the meantime have been furnishing a third of the MTV-program (see the following survey in fig. 1).

Fig. 1: Distribution of Programmes scheduled by MTV (2000-2007; workdays)

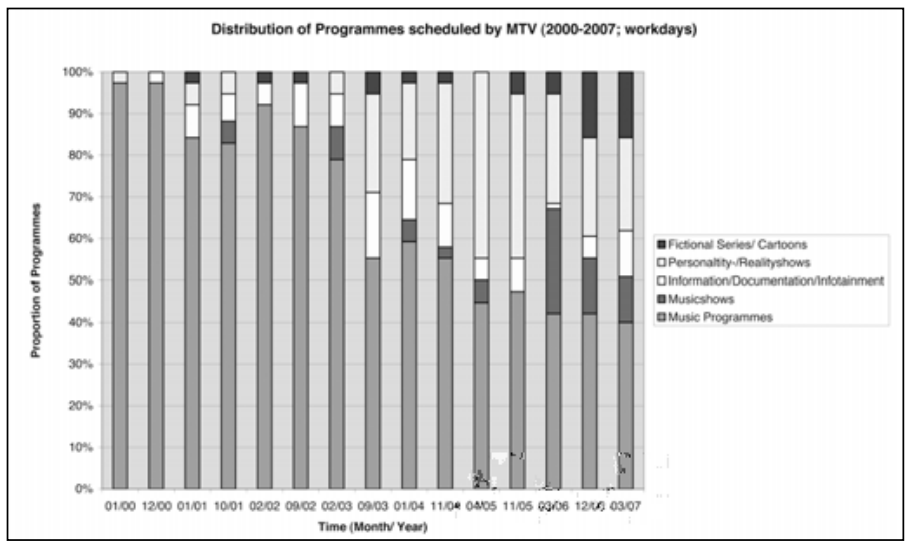

Bereitgestellt von | Universitaetsbibliothek Basel 
It is clear to see that there are still formats which are further orientated on popular music, but they are just making up only half of the program. This impression is enhanced by the fact that music video formats have been shifting towards the off-peak times (morning, afternoon). Other formats are now dominating their former program spaces, mainly personality- and reality-shows (around $20 \%$ ), cartoon series, and Animés for adults (more than $15 \%$ ) and docu- and infotainment-formats (around $10 \%$ ).

Dissolutions of boundaries concern not only programming, but distribution as well. Despite the dynamics in this field, a sketch-like overview of the different efforts music channels have made in the areas of digital TV, Internet, and mobile phone industry will be delivered in the following. ${ }^{3}$

\section{MTV digital}

A look at the efforts of MTV in the realm of digital TV reveals two distinct strategies. First, the main programs of the channel are, as before, receivable in an analogue way (via satellite or cable), while the additional digital content can be ordered by paying a monthly fee (starting from 2,99 Euro) (under the label 'MTV Tune-Inn' there are seven additional digital channels in supply). This trend will continue since digital TV should be introduced to Germany nationwide up to 2010. At the moment, music(-video) shows are mainly shifted into the package of additional, payable TV-offers which finds itself moreover in concurrence with the free online supplies.

\section{MTV mobil}

Of interest in the area of the mobile phones is the effort to make a pre-produced MTV-program receivable on a mobile device. This format is being referred to as "MTV mobil". Predestined formats of the so-called "HandyTV" ("mobile phone-TV") are tele-shopping, music videos, and so-called Mobisoaps (soap operas for the mobile phone) - perfectly modeled for music channels in the style of MTV, as also Dieter Gorny emphasizes with the slogan "We're the kings of the short attention span". Thus, the music channel - acting as a forecaster in this area - has been available from reception via mobile phone since summer 2006 . The broadcasting works via UMTS-technique in collaboration with the mobile phone companies T-Mobile, O2, and Vodafone. The channel MTV Music (an affiliation of Tune-Inn) can be received as along with a supply which shows daily updated programs of 60 minutes in an endless loop and which goes (depending from the cooperating partner) under the names MTV Shorts, MTV Snax or MTV mobile.

\section{MTV in the Net}

Contrary to the traditional business area of music channels, the TV market, PC, and Internet represent not only an additional possibility for pro- 
gram distribution, but they should be considered as media genres in their own right, replete with their own rules, rules which threaten to substitute music television in its function as a medium for offering music videos and as a forum for pop culture. The engagement of the music channels in this area is thus the biggest and most complex. One can discern the following areas:

- First the usual web presences have to be mentioned; we refer here to the websites of the two big music channels in the German-speaking countries (MTV und Viva), which - with their rate of more than 10 million page impressions - were well frequented in 2006.

- The main focus, however, should be on the Streams and Video-on-demand-supplies. Considering the Streams MTV got a double concurrence from ca. 2005 on: First, a series of so-called "Videoportals" (such as YouTube or MyVideo) began where also - among others - music videos were (illegally) supplied. Moreover, alternative supplies concerning the music television (such as tunespoon.tv) and sites offering live-concert-footage (see www.fabchannel.com) established themselves. The reactions of the music channels were ambivalent (comparable to those of the record company towards music stock exchanges à la Napster): On the one hand the Viacom-trust defended itself against the usage of illegal (meaning: copyrighted) contents (see the claim for damages against Google/YouTube). On the other hand communities of interest are sought and forged: Thus, the Viacom-corporation signed a cooperation-contract with the YouTube-concurrent Joost in order to do something against such competitors. Another project in the area of the Video-Stream and so to say - belated response to clip portals à la YouTube is the online-video-network iFilm, acquired in October 2005, which since then has been a member of the MTV Networks-family. A year later, in August 2006, Viacom bought the video- and entertainment-portal A-tom Entertainment Inc. for a sum of 200 million US-Dollars. Moreover, MTV in July 2006 started the German version of its Video-on-Demand online-service MTV Overdrive with great success, a service that allows the viewer to assemble his own program. The focus of the supply is on music videos, and the numbers of the Self-Made-MTV show how high the interest in the clips seem to be: In the first two weeks after the start of Overdrive the traffic on the homepage of the channel had doubled to 11,1 million page-impressions.

- Another area, prone to expand, is the one of the Online-Communities and of the interactive "Net-TVs". Among info- and media-supplies in the context of traditional homepages, it is here especially a range of Web 2.0-supplies which seem to be made as platforms for advertising. The so-called "Social Network Sites" (such as for example MySpace) enable users to build a virtual network of virtual interactivity and relationships. Even more drastic than in the case of the video portals it becomes clear which significance of the strategies of advertising the new supBereitgestellt von | Universitaetsbibliothek Basel 
plies have for the music channels: MySpace not only has the potential to make stars and to set new trends (MySpace-founder Tom Anderson is quoted in the weekly magazine Der Spiegel [15.01.2007] with the words "We have replaced MTV"). Moreover, Online-Communities and their offerings seem to be the forecasters of a new, changed behavior of media consumption apart from any given TV program in favor of selfcreated content and the ability to share this content interpersonally via the Internet. MTV has made an effort to participate in this potential: The platform MTV Flux is supposed to be run in the style of an OnlineCommunity. It has to be seen how far this will be successful. Up to now MTV Flux is only available in Great Britain and in Ireland.

\section{Conclusion: Changed (Conditions of) Reception}

It should now be clear that music videos and music television have been and still are exposed to processes of the dissolution of the boundaries on many different levels (genre, context of presentation/concurrence, TVprogram, distribution, areas of commerce, advert-alliances), and that this has had serious consequences for the framing conditions of the reception of the music video.

This shall be put into the following theses:

\section{Emancipation}

The dissociation of the phenomena 'music video' and MTV from each other due to processes of the dissolution of the boundaries on both sides not only indicates a separation, but - in a certain way, also - an emancipation: in the case of music television, it has been emancipated from its former trademark and flagship, the music video. In the case of the music video, it has been released from the framing broadcasting station, the music television. These emancipations create new latitudes for each.

\section{De-Framing}

The dissolution of the boundaries of music television comes with the consequence that the music video lacks its traditional context. It appears there as "among others" and is, moreover, outside the music television enclosed by a more diffuse program scheme which is missing the usual context. The "dissolution of the boundaries" of the music video on the level of genre also means that the product itself becomes more diffuse and that the frontier between the music video and the AV-clips area becomes more liquid. The once clearly situated phenomenon 'music video' has therefore lost its clear frame. 


\section{Shift of Meaning}

Processes of emancipation and of de-framing together with the processes of music television becoming increasingly ubiquitous (MTV looses its "cult" status) are having an opposed double movement: First, the music video generally looses signification and experiences a relativization on the "highways" of mass communication (here: especially analogue television), in order to, secondly, have a renaissance on the Internet, aside from the classical mass communication. This renaissance means an increase in significance and - regarding the reception of the music video - an intensification, since chosen video clips (can) get received on the Internet. The significance of the music video therefore appears to have been shifted: instead of being cost-neutral contents of commercial TV-stations and tied to a program, they appear today as free floating entertainment- and information-segments of the popular culture.

\section{Diversified Contexts of Reception}

The reception of the music videos thus falls apart under these conditions.

- This - with respect to the product -

a. in an area of classic music video which has gone into niches and gets enjoyed only by minorities (such as boarder zones in the music television, special supplies on the net, digital Pay-TV, DVD-Sampler);

b. as well in an area of the "clips" in the broadest sense, where more and more also music videos are received (for example on YouTube), while they appear, however, to more and more dissolve into the more general category of the audio-visual.

- And the reception of the music video furthermore falls apart with respect to the production/distribution

c. in a classic (mass media/program structured) TV-area

d. as well as into a net-area where mass-media and interpersonal communication are interfering.

\section{5. "Short Form"}

Despite the dissolution of the social-economic structures in which the music video "grew up", it not only persists as a medial genre, but seems to have permeated the whole of popular culture in the form of aesthetic traditions of creating and shaping and ways of reception.

a. This concerns on the one hand ways of creating and fashioning television in general as well as the shaping of the full program of the music channels in particular (predominating is a style, oriented upon the "clips-aesthetics": fast editing, emphasized combination with music, 
unconventional perspectives and movements of the camera; shows such as "Viva la Bam" appear as "clip-like").

b. Regarding classical forms of TV programming, this concerns, moreover, the form of the so-called "en passant viewing", provoked by the music videos and music television. This means, first of all, that full attention is dedicated not to the medium, but that the reception of media is embedded into other complexes of activities respectively happens parallel to them. Moreover, smaller and associatively connected units (keyword: "snippet-culture") allow a floating stepping in and out of the running program, thus favoring what has been called "Channel-Hopping".

c. This principle of the "short form", already laid out by music television has been completed by related supplies on the net: The program as a structuring principle has disappeared in favor of individual, user-directed AV-collages. "Channel-Hopping" is unnecessary, since there are no fixed programs and the phenomenon of the "en passant viewing" seems to become its opposite while at the same time becoming all-embracing: "To view clips in video portals" breaks down into the organizing activity (waiting until a clip has been uploaded, new orientation and choice etc.) which invites the viewer to engage in side-activities and pauses on the one hand as well as to islands of attention (targeted viewing of the clips) on the other hand.

Summing up, one can state that the "classical" reception of music videos has been enormously fragmented and differentiated (distraction), while the formal traditions of designing a clip (as a short form, an "annex", as simply made, as trenchant, as associative etc.) as well as ways of linked reception seems to have got extended and to have been popularized (pooling).

\section{REFERENCES}

1 | This paper summarizes the core results of our latest study Viva MTV reloaded (Schmidt, Neumann-Braun, Autenrieth 2009).

2 | See Banks 1996 and Schmidt 1999.

3 | This represents the state of research in Autumn 2007.

\section{BibLIOGRAPHY}

Banks, Jack (1996): Monopoly Television. MTV's quest to control the music, Boulder: Westview Press.

Schmidt, Axel (1999): "Sound and Vision go MTV. Die Geschichte des Musiksenders bis heute". In: Klaus Neumann-Braun (ed.), Viva MTV. Popmusik im deutschen Fernsehen, Frankfurt/M: Suhrkamp, p. 93-131.

Schmidt, Axel/Neumann-Braun, Klaus/Autenrieth, Ulla (2009): Viva

$M T V$ reloaded. Baden-Baden: Nomos. 
Bereitgestellt von | Universitaetsbibliothek Basel

Angemeldet

Heruntergeladen am | 18.09.18 17:30 